09

\title{
Изменение оптических характеристик полимерного композиционного материала при радиационном воздействии
}

\author{
(C) Н.И. Черкашина, А.В. Павленко \\ Белгородский государственный технологический университет им. В.Г. Шухова, \\ 308012 Белгород, Россия \\ e-mail: natalipv13@mail.ru
}

(Поступило в Редакцию 5 марта 2017 г.)

Представлены данные по синтезу полимерных композитов на основе полистирола и модифицированного $\mathrm{SiO}_{2}$. Исследована зависимость влияния концентрации $\mathrm{SiO}_{2}$ на поверхностные (терморегулирующие) свойства полученных композитов. Изучена микроскопия поверхности композитов с различной концентрацией $\mathrm{SiO}_{2}$. Установлено, что введение больших концентраций $\mathrm{SiO}_{2}$ приводит к образованию незначительного количества агломератов шарообразной формы, при концентрации 30 mass.\% $\mathrm{SiO}_{2}$ их размер может достигать $80 \mu \mathrm{m}$. Проведен анализ изменения интегрального коэффициента поглощения солнечного излучения разработанных полимерных композитов после воздействия вакуумного ультрафиолетового излучения при температуре $125^{\circ} \mathrm{C}$.

DOI: 10.21883/JTF.2018.04.45728.2237

\section{Введение}

Важнейшую роль в обеспечении длительной безотказной работы космических аппаратов (КА) играет стойкость их конструкционных материалов и элементов бортового оборудования к воздействию окружающей космической среды. По оценкам отечественных и зарубежных экспертов, более половины отказов и сбоев в работе бортовой аппаратуры КА обусловлено неблагоприятным воздействием факторов космического пространства. Некоторые из воздействующих факторов, например солнечное ультрафиолетовое излучение, оказывают влияние лишь на приповерхностные слои материалов, в особенности на терморегулирующие покрытия (ТРП), наносимые на поверхность КА для стабилизации его температурного режима [1,2].

С точки зрения повреждающего воздействия солнечного излучения в космосе на материалы особый интерес представляет УФ излучение с длинами волн короче $200 \mathrm{~nm}$ - вакуумное ультрафиолетовое излучение (ВУФ), энергия квантов которого (более $6 \mathrm{eV}$ ) достаточна для разрыва молекулярных связей в полимерных материалах [3]. Различие между ультрафиолетовым и рентгеновским излучениями с физической точки зрения состоит в том, что первое возбуждает внешние, а второе - внутренние электронные оболочки. Поскольку химические и физические свойства вещества определяются внешними электронными оболочками, так как поглощение радиации в ультрафиолетовом диапазоне спектра и определяет характер воздействия этих излучений на материалы, находящиеся в космосе.

Известно, что воздействие ВУФ на ТРП приводит к изменению оптических характеристик материала таких как интегральный коэффициент поглощения солнечного излучения $\left(\alpha_{s}\right)$ и коэффициент излучения (степень черноты), что приводит к нарушению температурного режима КА [4]. В настоящее время ведутся исследования по разработке новых составов терморегулирующих покрытий, обладающих высокими эксплуатационными и техническими характеристиками (адгезия к материалу корпуса, оптических и электрофизических характеристик, стойкости к факторам космического пространства) [5-7]. Особое внимание уделяется исследованию создания терморегулирующих покрытий на основе полимеров и их композитов, так как использование тяжелых металлов в космосе нежелательно из-за возникновения интенсивного тормозного излучения, усиливающегося при увеличении энергии падающих электронов, поэтому облегченные полимерные композиты могут стать альтернативной заменой существующим материалам [8].

Технология получения полимерных композитов нацелена на создание материалов, в которых путем направленного сочетания компонентов (полимерной матрицы и наполнителей различной природы) достигаются заранее заданные свойства. Такой способ получения полимерных композитов дает возможность создавать принципиально новые и разнообразные материалы с повышенными эксплуатационными, механическими, оптическими характеристиками и улучшенными специальными свойствами [9-12].

Целью настоящей работы является создание полимерных композитов на основе полистирола, наполненного модифицированными наночастицами диоксида кремния $\left(\mathrm{SiO}_{2}\right)$, а также исследование влияния наполнителя на поверхностные свойства полученных материалов при воздействии ВУФ.

\section{Материалы и методы}

В качестве полимерной матрицы для композитов использовали полистирол (ПС) марки УПС-803Э. ПС имеет химическую формулу $-\left[-\mathrm{CH}_{2}-\mathrm{C}\left(\mathrm{C}_{6} \mathrm{H}_{5}\right) \mathrm{H}-\right]_{n}$. 
Таблица 1. Основные свойства ПС

\begin{tabular}{c|l|c}
\hline № & Характеристика & Значение \\
\hline 1 & Плотность, $\mathrm{kg} / \mathrm{m}^{3}$ & 1050 \\
2 & Молекулярная масса, $\mathrm{g} / \mathrm{mol}$ & $10^{5}$ \\
3 & Температура стеклования, ${ }^{\circ} \mathrm{C}$ & 93 \\
4 & Твердость по Бринеллю, МРa $^{2}$ & 158 \\
5 & Относительное удлинение при разрыве, \% & 1.5 \\
6 & Удельное электрическое сопротивление & $10^{14}$ \\
& при температуре $20^{\circ} \mathrm{C}, \Omega \cdot \mathrm{m}$ & \\
7 & Водопоглощение, \% & 0 \\
8 & Предел прочности при растяжении, МРа & 40 \\
9 & Теплостойкость по Вика, ${ }^{\circ} \mathrm{C}$ & 100 \\
10 & Радиационный индекс & $8.0(50 \mathrm{~Gy} / \mathrm{s})$
\end{tabular}

Основные свойства исходного полистирола представлены в табл. 1.

Наполнителем служили наночастицы диоксида кремния $\left(\mathrm{SiO}_{2}\right)$, полученные гидролизом этилового эфира ортокремниевой кислоты, или сокращенно тетраэтоксисилана (ТЭОС) по золь-гель технологии. Золь-гель-метод по сравнению с традиционной схемой синтеза веществ обладает упрощенной технологией. Данный метод позволяет достичь высокой степени чистоты продуктов на всех стадиях синтеза при минимуме затрат на ее достижение $[13,14]$.

Важными факторами, определяющими физико-механические свойства полимерных композитов, являются адгезионное взаимодействие наполнителя и связующего, а также равномерное диспергирование наполнителя в объеме полимерной матрицы [15-17]. Такое взаимодействие частиц наполнителя с полимером может быть достигнуто различными путями, из которых наибольшее значение имеет поверхностная химическая модификация наполнителя [18-21].

Полученный диоксид кремния является гидрофильным веществом. Для более равномерного распределения наполнителя в полистирольной матрице и придания ему гидрофобных свойств была проведена химическая модификация наполнителя. В настоящей работе для модифицирования частиц наполнителя использовали жидкость гидрофобизирующую 136-41. Она представляет собой вязкую бесцветную маслянистую жидкость, легкорастворимую в большинстве органических растворителей, но нерастворимую в воде. Ее состав описывается формулой $\left[\mathrm{C}_{2} \mathrm{H}_{5} \mathrm{SiHO}\right]_{n}$ (где $\left.n=10-15\right)$, содержание активного водорода $1.3-1.45 \%$.

Изготовление образцов полимерных композитов на основе ПС и модифицированного диоксида кремния производилось по расплавной технологии. Как известно, создание эффективных полимерных композитов на основе термопластов возможно с использованием различных методов, из которых наиболее перспективным является экструзионный метод введения наполнителя в объем полимера через его расплав. Одним из основных достоинств этого метода по сравнению с растворной тех- нологией и полимеризацией in situ является отсутствие многостадийности процесса и растворителей [22-24].

Вначале смешение компонентов в сухом состоянии проводили в шаровой мельнице с минимально возможной загрузкой шаров (не более $15 \%$ ). После этого происходило формование образцов композитов путем загрузки в пресс-форму, нагретую до $180^{\circ} \mathrm{C}$, выдержки при данной температуре около часа и прессование полученного расплава. Концентрация наполнителя в полимерном композите варьировалась от 0 до $30 \%$.

Оценка степени диспергирования частиц модифицированного диоксида кремния в объеме полимерной матрицы производилась на основе микрофотографий поверхности композитов, полученных с использованием сканирующего электронного микроскопа высокого разрешения TESCAN MIRA 3 LMU.

Облучение разработанных составов полимерных композитов проводилось в „Специализированной установке для технологических и специальных испытаний образцов из полимеркомпозитов“, расположенной в аккредитованном в „ВНИИФТРИ“ (Москва) Центре „Радиационного мониторинга“ в БГТУ им. В.Г. Шухова (аттестат аккредитации № CAPK RU.0001.443195) (Белгород).

Интенсивность ВУФ в эксперименте составляла $0.5 \mathrm{~W} / \mathrm{m}^{2}, \lambda=90-115 \mathrm{~nm}$, давление в камере не превышало $10^{-5} \mathrm{~Pa}$. Испытания на стойкость полимерных материалов к воздействию ВУФ излучения проводили согласно стандартной методике по ГОСТ Р 25645.338-96.

Разработанные композиты помещались в камеру, затем в течение часа происходило их обезгаживание под воздействием вакуума с давлением $10^{-5} \mathrm{~Pa}$. Эксперимент по облучению ВУФ проводили в течение $24 \mathrm{~h}$. Спектры отражения композитов регистрировали с помощью спектрофотометра UV-3600 в Санкт-Петербургском Ресурсном центре „Методы анализа состава вещества“. Спектры $r_{\lambda}$ регистрировали в диапазоне $0.24-2.02 \mu \mathrm{m}$ по точкам с шагом $0.5 \mathrm{~nm}$.

\section{Результаты и их обсуждение}

Электронные микрофотографии поверхности полученных полимерных композитов на основе ПС матрицы и модифицированного диоксида кремния представлены на рис. 1. Как видно из микрофотографий поверхности (рис. 1), при концентрации наполнителя 10 mass.\% диоксид кремния достаточно равномерно диспергируется в объеме ПС матрицы, местами наблюдается незначительное количество агломератов шарообразной формы, в диаметре не превышающем $20 \mu \mathrm{m}$ (рис. $1, b$ ). Введение больших концентраций частиц диоксида кремния приводит к увеличению размеров агрегатов (рис. $1, c, d$ ). Так, при концентрации 20 mass.\% $\mathrm{SiO}_{2}$ (рис. $1, c$ ) их размер может достигать $40-60 \mu \mathrm{m}$, а при концентрации 30 mass.\% $\mathrm{SiO}_{2}$ (рис. $1, d$ ) их размер может достигать $80 \mu \mathrm{m}$. 


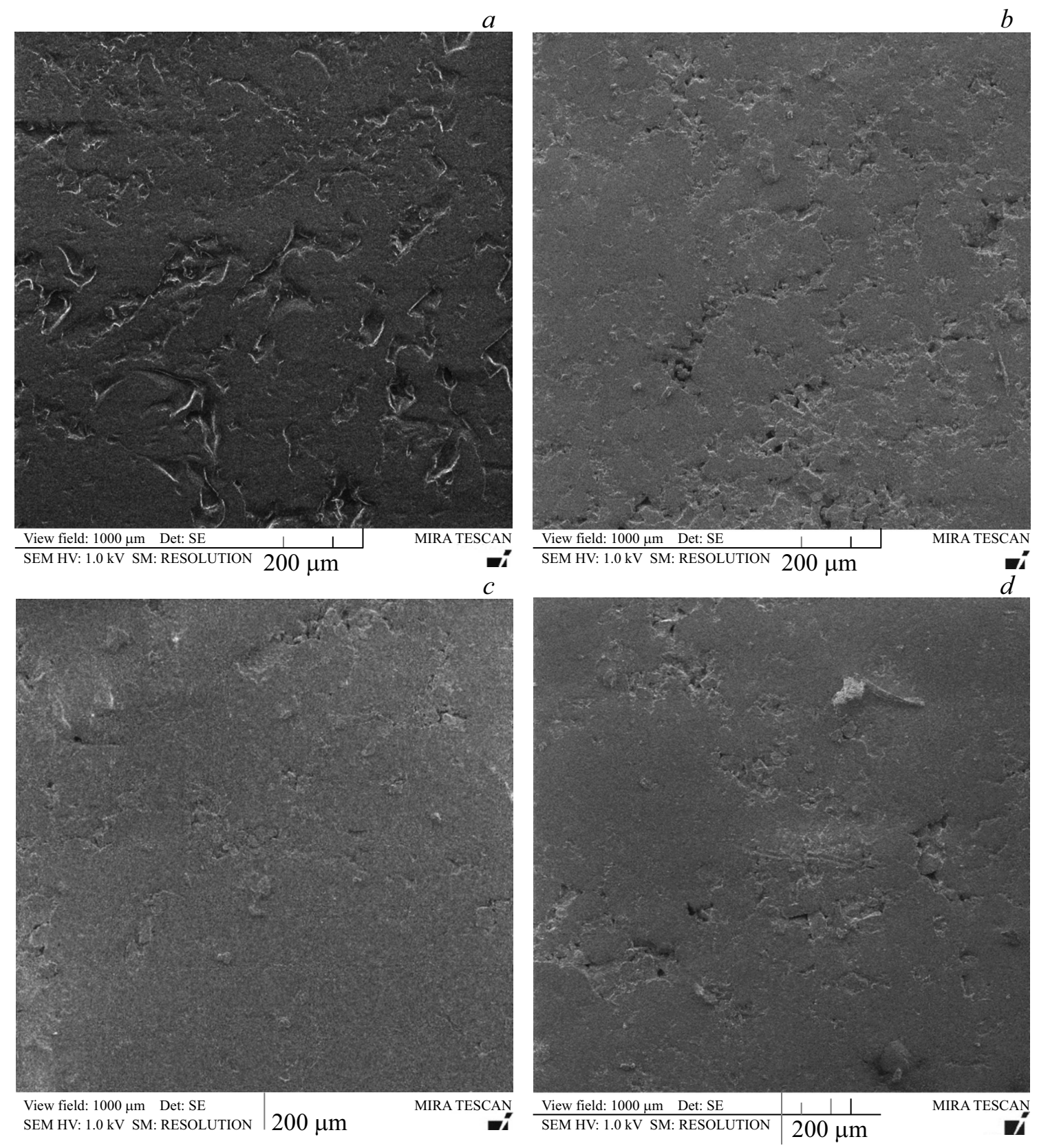

Рис. 1. Микрофотографии поверхности разработанных композитов: $a-$ чистый ПС, $b-10, c-20, d-30 \mathrm{mass}^{\circ} \% \mathrm{SiO}_{2}$.

Полученные образцы полимерных композитов подвергли обработке ВУФ в течение $24 \mathrm{~h}$. Далее были исследованы поверхностные характеристики композитов до и после обработки ВУФ. Интегральный коэффициент поглощения $\alpha_{s}$ - основная характеристика терморегулирующих покрытий (ТРП), вычисляли исходя из величин коэффициентов отражения по формуле:

$$
\alpha_{s}=1-R_{s}=1-\frac{\int_{\lambda_{1}}^{\lambda_{2}} J_{\lambda} \cdot \rho_{\lambda} d \lambda}{\int_{\lambda_{1}}^{\lambda_{2}} J_{\lambda} \cdot d \lambda}=1-\frac{\sum_{i=1}^{n} \rho_{\lambda i}}{n},
$$

где $R_{s}$ - интегральный коэффициент отражения солнечного излучения, $r_{\lambda}-$ значение коэффициента отражения композита при длине волны $\lambda ; n-$ число равноэнергетических участков солнечного спектра $(n=24)$. Значения длин волн, соответствующие равноэнергетическим участкам Солнца, представлены в табл. 2

В табл. 3 представлены данные интегрального коэффициента поглощения солнечного излучения $\left(\alpha_{s}\right)$ разработанных полимерных композитов до и после воздействия ВУФ при температуре $125^{\circ} \mathrm{C}$.

Анализ данных табл. 1 показал, что при увеличении концентрации наполнителя с 10 до 30 mass.\% значительно, практически в два раза, снижается значение ис- 
Таблица 2. Значения длин волн, соответствующие равноэнергетическим участкам Солнца

\begin{tabular}{c|c|c|c|c|c|c|c|c|c|c|c|c}
\hline № точки & 1 & 2 & 3 & 4 & 5 & 6 & 7 & 8 & 9 & 10 & 11 & 12 \\
\hline $\begin{array}{c}\text { Длина } \\
\text { волны, } \\
\text { nm }\end{array}$ & 315 & 366 & 408 & 437 & 463 & 490 & 518 & 547 & 576 & 607 & 639 & 673 \\
\hline № точки & 13 & 14 & 15 & 16 & 17 & 18 & 19 & 20 & 21 & 22 & 23 & 24 \\
\hline $\begin{array}{c}\text { Длина } \\
\text { волны, } \\
\text { пm }\end{array}$ & 712 & 754 & 801 & 855 & 915 & 984 & 1060 & 1160 & 1270 & 1420 & 1640 & 2020
\end{tabular}

Таблица 3. Основные оптические характеристики разработанных композитов до и после обработки ВУФ при температуре $125^{\circ} \mathrm{C}$

\begin{tabular}{c|c|c}
\hline \multirow{2}{*}{$\begin{array}{c}\text { Концентрация наполнителя, } \\
\text { mass.\% }\end{array}$} & \multicolumn{2}{|c}{$\alpha_{s}$} \\
\cline { 2 - 3 } & $\begin{array}{c}\text { До обработки } \\
\text { ВУФ }\end{array}$ & $\begin{array}{c}\text { После } \\
\text { обработки } \\
\text { ВУФ }\end{array}$ \\
\hline 10 & 0.378 & 0.506 \\
20 & 0.215 & 0.273 \\
30 & 0.191 & 0.225
\end{tabular}

ходного интегрального коэффициента поглощения солнечного излучения. Установлено, что при концентрации 10 mass.\% $\mathrm{SiO}_{2}$ интегральный коэффициент поглощения солнечного излучения увеличивается на $34 \%$, при концентрации 20 mass.\% - на 27\%, при концентрации 30 mass. $\%$ - на $19 \%$.

Арбитражный критерий стойкости к воздействию ВУФ по ГОСТ Р 25645.338-96 для полимерных материалов состоит в увеличении интегрального коэффициента поглощения не более, чем на $25 \%$. Исходя из полученных данных (табл. 3) видно, что данному условию удовлетворяют только композиты с концентрацией 30 mass. $\% \mathrm{SiO}_{2}$.

На рис. 2 представлена кривая, построенная по точкам, получаемым вычитанием коэффициентов отражения до облучения $\left(r_{\lambda 0}\right)$ из коэффициентов после облучения $\left(r_{\lambda 1}\right): \Delta r_{\lambda}=r_{\lambda 0}-r_{\lambda 1}$. Данные на графике представлены для состава с концентрацией 30 mass.\% $\mathrm{SiO}_{2}$.

Анализ разностных спектров диффузного отражения композита с концентрацией 30 mass.\% $\mathrm{SiO}_{2}$ показал, что коэффициент отражения после обработки ВУФ больше всего изменятся в диапазоне 240-500 nm длин волн. Максимальное уменьшение коэффициента отражения на $5.1 \%$ по сравнению с исходным наблюдается при длине волны $280 \mathrm{~nm}$. После $490 \mathrm{~nm}$ величина разностных спектров диффузного отражения начинает уменьшаться, в основном в УФ и видимой областях спектра, это говорит о том, что в этой области обработка ВУФ приносит наименьший вклад в отражательную способность исследуемого композита. В ближней ИК области после обработки ВУФ изменения не превышают $1.5 \%$.

Изменение поверхности разработанных композитов после воздействия ВУФ приводит к изменению их микротвердости. Зависимость микротвердости по Виккерсу композитов от содержания модифицированного $\mathrm{SiO}_{2}$ представлена на рис. 3 .

Из полученных результатов (рис. 3) следует, что ВУФ обработка разработанного композита ведет к незначительному увеличению микротвердости композитов с различной концентрацией наполнителя.

Увеличение микротвердости материалов, очевидно, произошло из-за межмолекулярных сшивок в композите при ВУФ облучении. Сшивание приводит к созданию

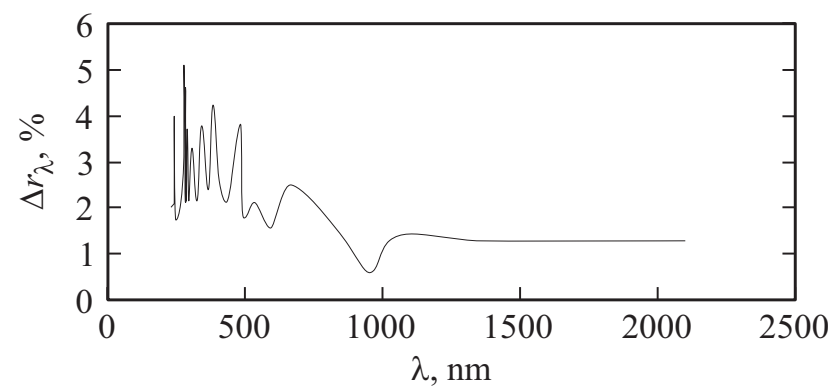

Рис. 2. Кривая зависимости разностных спектров диффузного отражения композита с концентрацией 30 mass.\% $\mathrm{SiO}_{2}$.

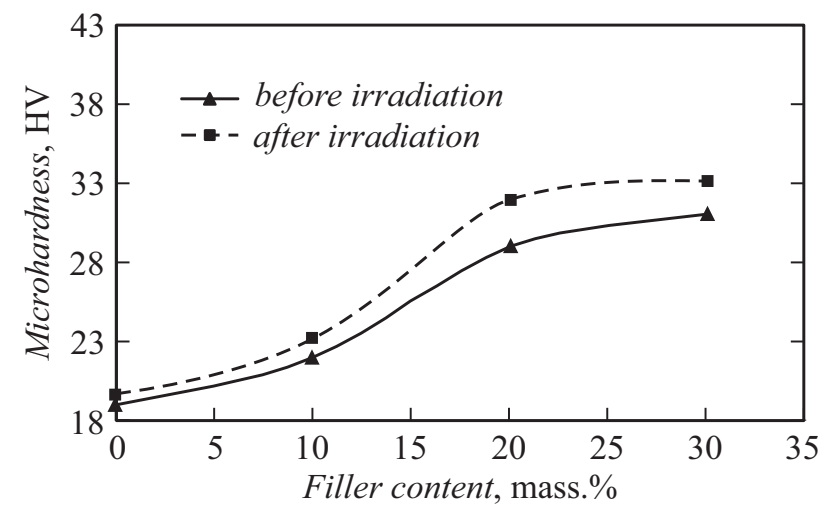

Рис. 3. Кривые зависимости микротвердости по Виккерсу композита от концентрации $\mathrm{SiO}_{2}$. 
барьерного слоя, снижающего диффузию низкомолекулярных продуктов деструкции и радикализации матрицы во внутреннее пространство, вследствие чего повышается микротвердость и поверхностная износостойкость полимера [25]. Выход сшивок и предельная концентрация их в поверхностном слое зависят как от условий обработки, так и в большей степени от структуры используемых материалов [25].

\section{Заключение}

В настоящей работе рассмотрена возможность создания полимерных композитов на основе полистирольной матрицы и нанодисперсного наполнителя. Наполнителем служили наночастицы диоксида кремния $\left(\mathrm{SiO}_{2}\right)$, модифицированные кремнийорганической жидкостью с целью придания им гидрофобных свойств.

Установлено, что при концентрации наполнителя 10 mass.\% диоксид кремния достаточно равномерно диспергируется в объеме ПС матрицы, местами наблюдается незначительное количество агломератов шарообразной формы в диаметре, не превышающем $20 \mu \mathrm{m}$, а введение больших концентраций частиц диоксида кремния приводит к увеличению размеров агрегатов.

В работе показано, что при увеличении концентрации наполнителя с 10 до 30 mass.\% значительно снижается значение исходного интегрального коэффициента поглощения солнечного излучения, практически в 2 раза. Установлено, что после обработки вакуумным ультрафиолетовым излучением композита с концентрацией 10 mass.\% $\mathrm{SiO}_{2}$ интегральный коэффициент поглощения солнечного излучения увеличивается на $34 \%$, с концентрацией 20 mass.\% - на 27\%, с концентрацией 30 mass.\% - на 19\%. Так как арбитражный критерий стойкости к воздействию ВУФ для полимерных материалов состоит в увеличении интегрального коэффициента поглощения не более, чем на $25 \%$, то данному условию удовлетворяют только композиты с концентрацией 30 mass. $\% \mathrm{SiO}_{2}$.

Исследование выполнено за счет гранта Российского научного фонда (проект № 17-79-10075).

\section{Список литературы}

[1] Боровикова О.В. // Междунар. научно-исследовательский журн. 2014. Вып. 11-1 (30). С. 15-18.

[2] Халиманович В.И., Харламов В.А., Ермолаев Р.А., Михеев А.Е., Гирн А.В. // Вестн. Сибирского гос. аэрокосмического ун-та им. акад. М.Ф. Решетнева. 2009. № 3. C. $110-113$.

[3] Рэнби Б., Рабек Я. Фотодеструкция, фотоокисление, фотостабилизация полимеров. М.: Мир, 1978. 676 с.

[4] Михайлов М.М. Фотостойкость терморегулирующих покрытий космических аппаратов. Монография. Томск: Изд-во Томского ун-та, 2007. 380 с.
[5] Хасаншин Р.Х., Надирадзе А.Б. // Поверхность: рентгеновские, синхротронные и нейтронные исследования. 2013. № 3. C. $73-78$.

[6] Новиков Л.С., Хасаншин Р.Х. // Физика и химия обработки материалов. 2013. № 5. С. 17-22.

[7] Хасаншин P.Х., Винтайкин И.Б. // Перспективные материалы. 2014. № 4. С. 5-12.

[8] Черкашина Н.И. // Современные проблемы науки и образования. 2012. № 3. С. 122.

[9] Jeon I.-Y., Baek J.-B. // Materials. 2010. Vol. 3. P. 3654-3674.

[10] Suprakas S.R., Masami O. // Prog. Polym. Sci. 2003. Vol. 28. P. $1539-1641$.

[11] Thostenson E.T., Li C., Chou T.-W. // Composit. Sci. Technol. 2005. Vol. 65. N 3-4. P. 491-516.

[12] Hanemann T., Szabo D.V. // Materials. 2010. Vol. 3. P. 3468-3517.

[13] Сигаев А.П. // Молодой ученый. 2014. № 21. С. 231-234.

[14] Иванов Л.А., Муминова С.Р. // Нанотехнологии в строительстве. 2016. Т. 8. № 2. С. 52-70.

[15] Павленко В.И., Черкашина Н.И., Иванищкий Д.А. // Вестник Белгородского гос. технологического ун-та им. В.Г. Шухова. 2016. № 10. С. 185-190.

[16] Глазков С.С. // ЖПХ. 2007. Т. 80. № 9. С. 1562-1567.

[17] Москалюк О.А., Самсонов А.М., Семенова И.В., Смирнова В.Е., Юдин В.Е. // ЖТФ. 2017. Т. 87. Вып. 2. С. 266-270.

[18] Черкашина Н.И., Павленко А.И. // Вестн. Белгородского гос. технологического ун-та им. В.Г. Шухова. 2016. № 9. C. 164-168.

[19] Etienn S., Becker C., Ruch D., Grignard B., Cartigny G., Detrembleur C., Calberg C., Jerome R. // J. Thermal Analys. Calorimetr. 2007. Vol. 87. N 1. P. 101-104.

[20] Wu W., Wagner M.H., Xu Z. // Colloid. Polym. Sci. 2003. Vol. 281. P. 550-555.

[21] Tang E., Cheng G., Ma X. // Powder Technology. 2006. Vol. 161. N 3. P. 209-214.

[22] Carotenuto G., Nicolais L., Kuang X., Zhu Z. // Appl. Comp. Mater. 1995. Vol. 2. P. 385-393.

[23] Yunhua Y., Yi.D. // Colloid. Polym. Sci. 2003. Vol. 281. P. 794-799.

[24] Stojanovic D., Orlovic A., Markovic S., Radmilovic V., Uskokovic P.S., Aleksic R. // J. Mater. Sci. 2009. Vol. 44. P. 6223-6232.

[25] Vasilets V.N., Nakamura K., Uyama Y. // Polymer. 1998. Vol. 39. № 13. P. 2875-2881. 